\title{
Giving or taking: the role of dispositional power motivation and positive affect in profit maximization
}

\author{
Markus Quirin · Martin Beckenkamp · Julius Kuhl
}

Received: 14 September 2007 / Accepted: 26 June 2008/Published online: 26 September 2008

(C) The Author(s) 2008. This article is published with open access at Springerlink.com

\begin{abstract}
Socio-economic decisions are commonly explained by rational cost versus benefit considerations, whereas person variables have not much been considered. The present study aimed at investigating the degree to which dispositional power motivation and affective states predict socio-economic decisions. The power motive was assessed both indirectly and directly using a TAT-like picture test and a power motive self-report, respectively. After 9 months, 62 students completed an affect rating and performed on a money allocation task (social values questionnaire). We hypothesized and confirmed that dispositional power should be associated with a tendency to maximize one's profit but to care less about another party's profit. Additionally, positive affect showed effects in the same direction. The results are discussed with respect to a motivational approach explaining socioeconomic behaviour.
\end{abstract}

Keywords Economic decision-making - Rational choice theory ·

Personality $\cdot$ Implicit power motive $\cdot$ Positive affect $\cdot$ Operant motive test

This research was facilitated by the Graduate School Integrative Competences and Well-Being funded by Deutsche Forschungsgemeinschaft (Grant 772/3).

\footnotetext{
M. Quirin $(\bowtie) \cdot$ J. Kuhl

Department of Psychology, University of Osnabrueck,

Seminarstraße 20, 49074 Osnabrueck, Germany

e-mail: mquirin@uos.de

J. Kuhl

e-mail: julius.kuhl@uni-osnabrueck.de

M. Beckenkamp

Max Planck Institute for the Research on Collective Goods,

Kurt-Schumacher-Str. 10, 53113 Bonn, Germany

e-mail: beckenk@coll.mpg.de
} 


\section{Introduction}

The nature of selfish versus prosocial behaviour in the context of limited resources challenges many disciplines like philosophy, biology, sociology, economics, and psychology. Despite high interest in this issue, the factors that influence socioeconomic decisions into the direction of selfishness or generosity have not been fully identified yet. And indeed, the situation, the actor's personality and affective states, and not least, interactions among these factors may influence socio-economic decisions. The present research investigates how the power motive, specifically the need for dominance, and the level of positive affect ${ }^{1}$ influence independent socioeconomic decisions, i.e. decisions taken without being influenced or receiving feedback by parties who are concerned in terms of being at advantage or at disadvantage (e.g., decisions about donations).

Important aspects of such independent decisions have been investigated in experimental economics via the so-called dictator game. In this game, one player makes a proposal of how to share sums of money to an anonymous other, whereas the other player does not have any influence on the decision. What factors may influence decisions in such a situation? Rational choice theory (RCT; cf. Heath 1976) assumes that people base decisions exclusively on economic, instrumental considerations, which is nicely expressed in the tag of man as homo oeconomicus (Rubinstein 1998, p. 8 f.). Thus, RCT would predict that individuals always take decisions that maximize their profit. Within this classical conception of man as homo oeconomicus, selfishness and rationality go hand in hand and are synonymous.

However, numerous experiments demonstrated that it is not the case that persons in a situation of independent decisions and anonymity are purely selfish and decide not to share (cf. Camerer 2003). Likewise, it could be demonstrated in numerous other experimental situations involving socio-economic decisions that people deviate systematically from the basic assumptions of classic RCT, suggesting that either influential constraints are not considered or the models are basically imperfect (e.g., Kahneman and Tversky 1996). Reviewing the extant literature on trust games, McCabe et al. (2003, p. 268) concluded that "there is ample evidence suggesting that a considerable proportion of play in two-person trust games deviates from that predicted by standard non-cooperative game theory - "a significant percentage of anonymously paired subjects arrive at cooperative outcomes." Consequently, people often are much less selfish than RCT would expect. Such results stimulated theoretical work on reciprocity and inequity aversion (cf. List 2007; Henrich et al. 2005).

But what kind of factors may moderate the balance between selfish and prosocial behaviour in rational decisions? As argued here, it is plausible to assume that individuals differ in the degree to which they behave individualistically or cooperatively. As outlined in the following section, this behavioural dichotomy may be associated with a personality trait commonly referred to as the power motive, and

\footnotetext{
${ }^{1}$ In recent years the distinction between incidental and integral affects has been made. Integral affect arises in direct response to stimuli, while incidental affect arises from unrelated stimuli that carry over into the decision (cf. Rogers and Bazerman 2008).
} 
this is why we were interested in investigating how this variable predicts socioeconomic decisions. Additionally, we argue that many results referring to the influence of affects on socio-economic decisions may be explained by a dynamic motivation approach. We think that such an approach may enrich current research about socio-economic decisions and mental states and may have the potential to integrate inconsistent results from this area of research.

\section{The role of the power motive}

In experimental economics, a variety of factors have been postulated and investigated that may provide explanations for non-selfish behaviour. For example a number of studies found that behaviour is influenced by fairness norms (Fehr and Schmidt 1999). In a similar vein, there is evidence supporting inequity aversion. Corresponding models that postulate that people dislike differences between one's own and others' payoff and that emotional arousals render them to deviate from personal profit maximization (e.g., Bolton and Ockenfels 2000; Fehr and Schmidt 1999; an extensive discussion of these approaches can be found in Nicklisch 2006). Moreover, it has been revealed that emotions and punishment-sentiments foster the enforcement of such fairness norms (Fehr and Gächter 2002; Gürerk et al. 2006).

In this article, we explore the role of the power motive in moderating socioeconomical behaviour. This motive refers to individual differences in the human tendency to be dominant and to achieve control over means that can be used to influence other individuals (Veroff 1957). Striving for status, dominance, superiority, or controlling positions are thus typical examples of manifestations of the power motive (Winter 1973). In this vein, an impressive finding is that differences in the strength of the power motive among the first 12 US presidents, as assessed through an analysis of their maiden speech, were associated with the number of cabinet changes and the number of war entries (Donley and Winter 1970; see also Winter 1987). There is no doubt that money is one, if not the strongest, means to influence others because money has been providing the basis for human's subsistence in most cultures for thousands of years. Possessing lots of money is a symbol of high status and control over others and should therefore be particularly rewarding to individuals who have a strong power motive compared to those who have a low power motive.

The power motive is inherently associated with the establishment of hierarchical relationships in which the person dominates over others. By contrast, fairness norms and inequity aversion refer to symmetrical relationships incompatible with the power motive to some degree. However, this does not imply that individuals with a high power motive never behave in a fair way. Rather, and in line with dynamic motivation theories (e.g., Kuhl 2001; Powers 1973) there are a variety of dynamic motivational sources integrated in an individual that compete to influence behaviour. For example, individuals high in power motivation may be fair in the presence of others because they may at the same time be sensitive to social reward or reputation, fostering socially desirable behaviour. By contrast, their tendency to behave in an individualistic way or even to strive for means that putatively increase 
control over others (e.g., money), is likely to outweigh potential fairness norms or inequity aversions in situations that do not permit feedback from others, as realized in the dictator game.

Two pioneer studies provided direct evidence of effects of the power motive on socio-economic behaviour (Schnackers and Kleinbeck 1975; Terhune 1968). In both studies, the authors indirectly assessed dispositional power using the Thematic Apperception Test (Murray 1943). In this test written stories about ambiguous pictures are analyzed and scored by experts for contexts related to the power motive according to standardized coding systems to provide an index of the "implicit" power motive (e.g., Uleman 1966; Veroff 1957; Winter 1973). First, Terhune (1968) had his participants play three different games using different variants of the broadly applied prisoner's dilemma game: a one-shot-game, and a repeated 30-period prisoner's dilemma, one run without communication and another run with communication. Individuals with a strong power motive turned out to be most competitive and exploitive players. Likewise, Schnackers and Kleinbeck (1975) had groups of three individuals play a bargaining game called "con game". Participants played dice and had power cards at their disposal with which they could multiply their points in order to approach the goal. Two players could form a coalition against the third player to achieve the goal jointly and to make agreements about how to share the payoff. Participants were allowed to violate and form coalitions as often as they wanted. The authors found that individuals with a strong power motive manipulated others in order to win the game. Specifically, high power motivation was associated with the number of propositions, formations, and violations of coalitions. Moreover, power motivation was associated with playing the other players off against each other, changing the payoff agreements for their own benefit, and winning the game.

The results of both studies are in line with findings from research on socioeconomic decisions showing that individuals who are concerned about their own payoffs (classified as selfish) strongly evaluate the behaviour of the other player in terms of potency, suggesting that selfish individuals understand social dilemmas as a situation of might rather than morality (cf. Liebrand et al. 1986; Van Lange and Kuhlman 1994). ${ }^{2}$

The notion that the power motive should play a role in socio-economic decisions is also compatible with more recent research on personality influences on socioeconomic decision-making. Scheres and Sanfey (2006) predicted socio-economic decisions by differences in the dispositional sensitivity towards rewarding stimuli, a trait that seems to be associated with high power motivation (Keltner et al. 2003). Specifically, participants played both the dictator game, as described above, and the ultimatum game. The ultimatum game is similar to the dictator game but differs in that the respondent can reject the offer of the proposing person and "burn" the whole money by this rejection. Consistent with the authors' expectations, participants with high sensitivity towards reward withheld more money in the

\footnotetext{
2 This again raises the question of how this sensitivity to power differences is related to two different motivations for defections: fear and greed. This undoubtly interesting question is not discussed in the paper at hand.
} 
dictator game. However, in contrast to their expectations, high sensitivity was associated with higher offers in the interactive ultimatum game, a finding that the authors attribute to a tendency of reward-sensitive individuals' initial attempts to maximize the likelihood of reward (which is higher in case of good offers in the ultimatum game, but is not able to be influenced in the dictator game). The amount of reward is considered as secondary criterion only, according to this view. In a study by Brandstätter and Königstein (2001), participants played the "ultimatum game with advance production", that is an ultimatum game where the stock of the ultimatum game is determined by a preceding common production that depends both on the investment of the proposing person and the respondent. Proposers high in the $16 \mathrm{PF}$ personality dimensions of independence and tough-mindednessaspects that should be inherently associated with the power motive-demanded higher return shares of the common investment than those low in these dimensions.

Theoretical considerations and empirical evidence reported above suggests that the power motive is a determinant of social-economic behaviour. Specifically, it may be assumed that a strong power motive implies an "egoistic" bias towards satisfying needs and goals of one's own rather than those of other individuals. Therefore, particularly in situations that do not permit social feedback on the decisions with the consequence that the influence of normative behaviour and social desirability tendencies is weakened, such as in the dictator game, the postulated tendency to maximize personal outcomes of individuals with high levels of power motivation should be uncovered.

\section{The role of affective states}

Additional research demonstrates the impact of affective states on socio-economic decisions. Many studies suggest that positive mood fosters prosocial behaviour and cooperation (cf. Carlson et al. 1988; Fessler and Haley 2003), and that affective states and emotions can influence economic decisions (Lerner et al. 2004). Although this idea seems plausible, contrasting findings have been reported that require more complex models for explanation (see Hertel 1999 for a review). For example, Hertel and Fiedler (1994) demonstrate that it is not positive affect per se that influences the degree of cooperativeness. According to their results, positive affect raises the behavioural variance and, therefore, positive affect has only an indirect influence on the probability for cooperativeness. If so, positive mood should particularly raise average cooperativeness if the individual was not yet cooperative before and has not yet developed a consistent strategy. Likewise, Hertel et al. (2000) only found indirect effects of mood on cooperation. Using an interactive game, they found that happy participants mimic the moves of their opponents, whereas sad participants make their moves on a more detached analysis of the game itself. This is congruent with the literature stating that happy participants are socially more interactive than sad participants (cf. de Mesquita and McDermott 2004).

According to personality systems interactions (PSI) theory (Kuhl 2000, 2001), positive affect plays an important role in decision-making. Specifically, PSI-theory holds that positive affect serves as a motor for the enactment of intentions see 
(Kuhl and Kazén 1999), for empirical evidence. Congruent with this notion, (Sanna et al. 2003, Study 4), using a resource dilemma game, induced either competitive or cooperative goals by manipulating the instructions. Individuals in positive mood as induced via music acted more competitively when having competitive goals in mind but more cooperatively when having cooperative goals in mind. In a similar vein, Hertel and Fiedler (1998) tested the influence of positive vs. negative attributes associated with either cooperation or competition in a socio-economic allocation task that was a modification of the ring-measure-value scale (Liebrand and McClintock 1988). If individuals were primed with to-be-learned negative attributes associated with competition (e.g., selfish, egocentric, arrogant, destructive, unfair, domineering, aggressive), they showed less cooperative behaviour. By contrast, if individuals learned positive attributes associated with cooperation (e.g., constructive, truthful, supportive, helpful, fair, etc.), they showed more cooperation.

Notably, individuals who derive positive affect from greediness rather than from fairness were more selfish in a dictator game, in which individuals have to make decisions on allocations independently, but not in an ultimatum game, in which the proposals of the individuals depend on the acceptance of the responders (Haselhuhn and Mellers 2005). These results suggest selfishness is a function of an interaction between positive affect, power motivation and structure of the game. If greediness cannot be punished, the power-motive and positive affect may raise selfish behaviour, whereas in situations where punishment or refusal is possible, positive affect and the power motive may raise the probability of investing in considerations or reasoning about how much selfishness the other will be willing to accept.

In sum, whereas many studies suggest that positive affect engenders prosocial behaviour, recent studies suggest more complex ways in which positive affect influences socio-economic behaviour, with some evidence even suggesting that positive affect can foster selfish behaviour, particularly in situations where independent individualistic goals are activated, as it is the case, for example, in dictator games.

\section{Present research and hypotheses}

The present work aims at investigating the degree to which decision-making in socio-economic situations depends on dispositional power motivation and affective states. Because personality tests are to some degree influenced by situational variables (Carver and Scheier 2004), applying a longer time period between assessments of the power motive and the behavioural task would ensure that our predictions are based on stable rather than transient variance of power motivation. Therefore, we capitalized on a longitudinal approach measuring both implicit and explicit (self-reported) power motives nine months prior to the assessment of socioeconomic decisions. Consequently, findings of relationships between power motive dispositions and behavioural outcomes would speak to the ecological validity of the study.

To assess the implicit and explicit power motive we used a recently developed TAT-like operant motive test (Kuhl et al. 2003) and a self-report measure of 
motives (Kuhl 2005; see also Kuhl et al. 2006), respectively. Affective states were assessed at the beginning of the experiment using the Positive And Negative Affect Schedule PANAS; (Watson et al. 1988). The PANAS allows for the assessment of positive and negative affect as two dimensions. Distinguishing between the two affective states is meaningful because they have shown to have differential effects on cognition and behaviour (cf. Kuhl 2000). A separate analysis of the role of positive versus negative affect would contribute to the yet unanswered question of which of the two affective components influences socio-economic decisions and in which way. After the application of the PANAS, socio-economic decisions were assessed with the ring measure of social values (Liebrand and McClintock 1988). In this measure, participants are asked to decide between two alternatives to share out a certain amount of money between him/herself and another party. The ring measure was originally conceptualized as a trait rather than a state measure of social values. However, each of the decisions in the ring measure of social values are similar to the dictator game and asking individuals to allocate amounts of money to oneself and another person is a real behavioural measure that can also be influenced by situational variables such as affect, the investigation of which constituted a major goal of the study. Consistent with this notion, the ring measure was successfully applied as a state (dependent) measure in previous research (e.g., Hertel and Fiedler 1998; Poppe and Valkenburg 2002). In contrast to the dictator game, in which participants are asked to divide a constant sum of money between themselves and an anonymous recipient, the ring measure provides the opportunity to maximize joint payoff and, as a result, to realize mutual benefit. Moreover, the final outcome depends on the decisions of both players, whereas in the dictator game each player determines the final outcome alone (cf. Brosig 2002).

We hypothesized that the power motive should be positively associated with selfish behaviour, i.e. the so-called "rational choice" to maximize the financial outcome of one's own. However, we have no clear-cut hypothesis about the relationship between the power motive and the degree to which one cares about the negative financial outcome of the other player, i.e. about a potential tendency to diminish the other's payoff ("competition" or "sadism"). Thus, we assumed that the power motive would be related to a non-social orientation in economical decisions if self-interest is in conflict with the social orientation. Additionally, we expected that positive affect would foster selfish decisions because those are taken independently, which was mentioned in the instruction. In this regard, the present task is very similar to the dictator game and therefore both the power motive and positive affect should directly influence selfish decisions.

\section{Method}

\subsection{Participants and course of the study}

Eighty-eight students (56 females and 32 males) studying diverse disciplines at the University of Osnabrueck participated in the study. They were between 19 and 39 years old $(M=24.2, \mathrm{SD}=4.2)$. The present study was part of a longitudinal 
study on the relationship of motives and affective states on cognition and behaviour. In a first session, participants completed a battery of personality questionnaires including the motive measures. Nine months later, all students were asked about their interest in taking part in the study. 62 individuals decided to take part. Participants were informed that the upcoming session would be about how people allocate certain amounts of money, without giving further details at this point of time.

Upon arrival, participants were separately situated in small booths equipped with a desk, a chair, and a computer. Participants completed the PANAS scale and were introduced to the "Money Allocation Game" (ring measure of social values), which requires assigning certain amounts of money to oneself and to another participant (see below). As an incentive, we paid between 2 and 12.80 Euro, according to the total payoff achieved by the participant in this session.

\subsection{Material}

\subsubsection{Power motive and affective states}

The Operant Motive Test (OMT; Kuhl et al. 2003; Scheffer et al. 2003) was used to measure individual differences in the implicit power motive. The OMT is a modified TAT technique (Murray 1943), in which participants are asked to invent a story for each of 15 schematic drawings of social interactions. Participants are instructed to expose their spontaneous associations to the following four questions without the necessity to write down the entire story: (1) "What is important for the person in this situation and what is the person doing?", (2) "How does the person feel?", (3) "Why does the person feel this way?", and (4) "How does the story end?". An example of typical power-related response may be: "The person on the picture is a guide and tells the tourists details about the town. He likes to be in the center of attention. He feels proud because the others are impressed about his knowledge. Finally, the tourists make a lot of compliments in the end, which the guide enjoys very much." Pictures that elicit a power theme (except for powerrelated anxiety) add a point on the power scale from 0 to 15 . OMT scoring was carried out by well-trained assistants who had (1) previously coded more than a thousand OMTs, (2) received continuous feedback concerning their agreement with expert ratings over a period of three years, and (3) reached an average inter-rater agreement above 0.85 . Evidence confirming the validity of the OMT has been reported in Baumann et al 2005; Kuhl and Scheffer (1999) and Scheffer (2001).

To assess the explicit power motive, we used the Power Dominance scale of the Motive Enactment Test (Kuhl 1999; see also Kuhl et al. 2006). This scale expresses the degree to which individuals describe their behaviour as being guided by strivings for dominance, status, and control over others. This scale consists of four items and has a Cronbach alpha of 0.72 (Kuhl 2005). The items of the scale can be rated as follows: (1) "not at all", (2) "somewhat", (3) "pretty much", and (4) "absolutely". An example item is "When I am in a group, I often express my opinions with vigour". 
We assessed affective states by the commonly applied positive vs. negative affect scales of the PANAS (Watson et al. 1988; for the German version, see Krohne et al. 1996). Based on 10 positive and 10 negative adjectives, participants are asked to rate their current affective states on a 5-point-Likert scale ranging from (1) very slightly or not at all to (5) extremely.

\subsubsection{Selfish versus prosocial behaviour}

To assess selfish and prosocial behaviour as the major criterion variables in the present study, we used a computerized form of the ring measure questionnaire of social values (Liebrand and McClintock 1988). The questionnaire contains 24 subsequently presented items, each representing two imaginary money distributions between oneself and a virtual other player. The participants were instructed to imagine that they played with an anonymous other person who receives the same items and that the individual outcomes were determined by the choices of both: the person herself and the other person. For example one item consists in a choice between alternative 1-15.00 Euro to oneself and 0.00 Euro to the other player-or alternative 2 with 14.50 Euro to oneself and 3.90 Euro to the other player. With respect to this item, alternative 1 is preferred by individualistic subjects, whereas a preference for alternative 2 indicates co-operative tendencies.

The ring measure questionnaire measures social values by assessing the value that participants attach to their own payoffs and the payoffs of others in socioeconomic allocations (see also Liebrand and Dehue 1996). The social value of a subject is represented by a vector from the center of the circle ("ring"). The ring is in a plane containing outcomes to self on the horizontal axis, and outcomes to other on the vertical axis. The angle of the vector gives the social values orientation. An angle of $-45^{\circ}$ refers to competitive, an angle of $0^{\circ}$ to individualistic, and an angle of $45^{\circ}$ to cooperative decisions. The length of the vector gives the respective reliability of the measure and thus refers to the degree to which a person showed consistency in his responses on 24 socio-economic allocation tasks.

Because the angle measure of social value orientation is a compound of self and other assignments, the differential influence of psychological variables on the tendency to maximize one's own profit (individualistic tendencies) and the tendency to maximize the profit of another person (prosocial tendencies) cannot be investigated. Therefore, we decided to additionally investigate correlations of psychological variables with the two independent dimensions of self versus other assignments separately. Self assignments versus other assignments are simply the sum of money a person assigns to himself versus to the other person, respectively. We expected to obtain more specific information about what dimension describing socio-economic decisions, i.e. individualistic versus prosocial, is related to the power motive or affect.

Participants were instructed as follows: In the following you will obtain a number of decision tasks in which you are asked to assign a certain amount of money to yourself and another party. The other party is another participant in this study who was randomly assigned to you as a player. In each of the decision tasks, you can 
always choose between two options defining how the sum of money can be shared out between you and the other person. The other person has been received exactly the same tasks. Note that your payoff depends on both the way you make your decision and the way the other person makes his/her decision. The same is valid for the other person's payoff. You will receive the money, which will be between 2 and 12.80 Euro after the experiment.

\section{Results}

In the present study, three individuals showed consistency values of zero and were therefore removed from data analysis. Thus, we went on with data from 59 participants. Table 1 shows Pearson correlations between social behaviour variables, implicit and explicit power motive, and positive and negative affect. Congruent with our hypothesis, the implicit power motive inversely predicted social values orientation, $r=-0.26, p<0.05$. By contrast, the explicit power motive was unrelated to social values orientation, $r=-0.11$, ns. Likewise, positive and negative affect were unrelated to social values orientation, $r=-0.06$, ns, and $r=-0.09$, ns, respectively.

To provide a microanalysis of the relationships of power motive and positive affect with social behaviour, we had a more thorough look at how the score for social values orientation is composed of selfish and prosocial behavioural components (self- vs. other- allocation, respectively) and how those are related to the power motive and affect. The high positive correlation of social values with other-allocation, $r=0.93, p<0.001$, and the weaker but nevertheless highly significant negative correlation of social values with self-allocation, $r=-0.44$, $p<0.001$, should not be interpreted empirically, but is a property that can be

Table 1 Intercorrelations, means, and standard deviations for scores on ring measure of social values, implicit and explicit power motive, and affective states

\begin{tabular}{|c|c|c|c|c|c|c|c|c|c|c|}
\hline Measure & 1 & 2 & 3 & 4 & 5 & 6 & 7 & 8 & M & $\mathrm{SD}$ \\
\hline \multicolumn{11}{|l|}{ Ring measure } \\
\hline Social values & - & $-0.44 * *$ & $0.93 * *$ & 0.07 & -0.11 & $-0.26^{*}$ & -0.06 & -0.09 & 24.52 & 31.78 \\
\hline Self-allocation & & - & $-0.42^{* *}$ & $0.65 * *$ & $0.25^{\mathrm{t}}$ & $0.36^{* *}$ & $0.40 * *$ & -0.07 & 20.10 & 6.99 \\
\hline Other-allocation & & & - & 0.14 & -0.11 & -0.13 & -0.04 & -0.10 & 9.64 & 11.38 \\
\hline Consistency & & & & - & 0.18 & 0.17 & $0.32 *$ & -0.04 & 25.48 & 4.84 \\
\hline \multicolumn{11}{|c|}{ Individual motives } \\
\hline Explicit power & & & & & - & 0.10 & $0.40 * *$ & $-0.26^{*}$ & 6.03 & 2.09 \\
\hline Implicit power & & & & & & - & 0.20 & -0.16 & 5.49 & 1.80 \\
\hline \multicolumn{11}{|l|}{ Affective states } \\
\hline Positive affect & & & & & & & - & $-0.53 * *$ & 3.37 & 0.71 \\
\hline Negative affect & & & & & & & & - & 1.63 & 0.53 \\
\hline
\end{tabular}

$N=59 ; * p<0.05 ; * * p<0.01$ (two-tailed) 
deduced from the construction of the RMV-scale: A negative correlation between social values and self-allocation can be expected when the majority of the subjects has social values $\geq 0^{\circ}$ on the ring, ${ }^{3}$ as well as the negative correlation between self and other $(r=-0.44, p<0.001)$. However, it is interesting to find that selfish behaviour was highly positively correlated to behaviour consistency, $r=0.65$, $p<0.001$, whereas prosocial behaviour was not significantly correlated with behaviour consistency, $r=0.14$, ns. This is in line with findings from Liebrand and McClintock (1988) showing that cooperators and competitors have longer response latencies than altruists and individualists. In contrast to their interpretation, from our point of view this can be explained by social values being confounded with the possibility to make use of easy heuristics that nevertheless lead to consistent answers. Thus, an individualistic participant $\left(0^{\circ}\right)$ will always choose the alternative that gives him a higher payoff. However, with respect to a cooperative or competitive participant $\left(45^{\circ}\right.$ and $\left.-45^{\circ}\right)$ there is no such easy heuristic that guarantees consistent answers with respect to the 24 socio-economic decision tasks given in the ring-measure-value scale. To our knowledge, the problem that cognitive complexity may be confounded with the reliability of different social values measured by the Ring scale has not yet been discussed in the literature so far.

In line with our hypothesis, both the implicit and explicit power motive were associated with selfish behaviour, $r=0.36, p<0.01$ (one-tailed), and $r=0.25$, $p<0.05$ (one-tailed), respectively, but not with prosocial behaviour, $r=-0.13$, ns, and $r=-0.11$, ns. This finding suggests that the variance of social values orientation explained by the implicit power motive can be mainly attributed to the degree to which individuals care about their own outcome and not so much about relative advantages between the own outcome in relation to the outcome of the other person. ${ }^{4}$ To test whether the implicit or the explicit measure predicts selfish behaviour independent from each other, we conducted partial correlations. When the explicit power motive was partialed out, the implicit power motive and selfallocation remained significant, $r_{p}=0.35, p<0.01$. When the correlative influence of implicit power motive was removed, the explicit power motive remained to be significant, $r_{p}=0.23, p<0.05$ (one-tailed). This suggests that the effect of one type of power motive on self-allocations cannot be explained by the effect of the other type.

Whereas negative affect was unrelated to selfish behaviour, $r=-0.07$, ns, positive affect was positively related to selfish behaviour, $r=0.44, p<0.001$. However, positive affect was also associated with behavioural consistency, $r=0.32, p<0.05$, and behavioural consistency, in turn, was associated with individualistic behaviour, $r=0.28, p<0.05$. Therefore, it cannot be excluded that positive affect is only indirectly associated with selfish behaviour because participants having low motivation to perform the task correctly, as indicated by the consistency measure, receive a lower payoff because they do not endeavour to

\footnotetext{
3 A correlation of 0 would be expected, if the distribution above and below a social value of $0^{\circ}$ is the same.

4 Above that, the small and non-significant negative deviation of the low correlation from zero could also be explained by the relatively low number of social values below $0^{\circ}$.
} 
maximize their profit. To test this critical objection, we correlated positive affect and self-allocation, while we removed the correlative influence of behaviour consistency. Positive affect remained to be positively correlated with selfish behaviour, $r_{p}=0.27, p<0.05$. This suggests an influence of positive affect on selfish behaviour that is independent of the influence from the motivation to perform the task appropriately.

In a further set of analyses, we tested whether the effects of positive affect and power motive on selfish behaviour were independent from each other. In a first analysis, we included the power motive and positive affect as predictors of selfallocation in a multiple regression analysis after having centered these variables (Aiken and West 1991). We found that the effect on self-allocation remained significant for either variable, power motive, $\beta=0.29, p=0.016$, and positive affect, $\beta=0.35, p=0.004$. This suggests that the effect of one of the two variables on self-allocation cannot be explained by the effect of the other. Analogously, we conducted a multiple regression using the explicit power motive instead of the implicit one. In contrast to the implicit power motive, the explicit power motive became non-significant, $\beta=0.11, p=0.419$, when positive affect was included as a further predictor. Positive affect however remained a significant predictor, $\beta=0.36, p=0.009$. To test whether positive affect may mediate the effect of the explicit power motive on selfish behaviour, we drew on the Sobel test (see Baron and Kenny 1986), which was significant, $Z=2.14, p<0.032$.

\section{Discussion}

The present study investigated the degree to which the tendency to behave in a selfish or prosocial way in a limited-resource game of independent socio-economic decisions is a function of interindividual differences in dispositional power motivation and affective states. Because a high power motive is commonly associated with individualistic behaviour and status concerns, we hypothesized and confirmed that dispositional power, in particular if measured by the indirect test, inversely predicts social values orientation in economic decision-making. By contrast, affective states were unrelated to social values orientation but were strongly related to selfish allocations. This means that positive affect triggers selfish decisions but that it is unrelated to how people behave to others, i.e., either harmful (competitors) or benevolent (cooperators).

Consistent with our hypothesis, we found that implicit and explicit power motives showed independent effects, paralleling previous research on implicit and explicit motives in general and suggesting incremental validity of the implicit motive test. The power motive was unrelated to prosocial behaviour. This finding suggests that, in general, individuals with a high power motive don't care about the outcome of the other, which means that they do neither attempt to diminish the other's outcome ("competition") nor to increase the other's outcome ("cooperation"). It is important to note that the socio-economic situation was about mostly independent decisions and therefore it may not be generalized to interactive games in general. Indeed, the studies by Terhune (1968) and Schnackers and Kleinbeck 
1975), both of which used interactive games, showed that individuals with a strong power motive showed competitive behaviour in a one-shot game and cooperated on the long run in iterated games.

Our hypothesis of a positive relationship between power motive and selfish behaviour is strengthened by the fact that it was supported by two methodically different assessments of the power motive, a picture story test and a self-report test. At the same time, implicit and explicit power were positively but not nonsignificantly correlated, which is in line with the literature showing low or absent relationships between implicit and explicit motives (e.g., Bornstein 2002). This pattern of relationships suggests that different components of socio-economic decision-making may have been predicted by the two motives differentially, more spontaneous versus more controlled components, presumably (McClelland et al. 1989a, b). However, these components cannot be distinguished on the basis of the present data and may therefore be controlled for in future research.

The present study adds to the literature on influences of personality on socioeconomic decisions. Notably, much previous research on this issue produced indecisive results (for a review, see Thompson 1990), leaving several theorists to detach importance to personality as a potential determinant (e.g., Davis-Blake 1989; Lewicki et al. 1994). One reason for indecisive results may have been (1) a disregard of dynamic motivational factors and external conditions (different situations), which may strongly influence socio-economic behaviour, as well as (2) an almost exclusive usage of self-report personality measures. Our results suggest that the power motive has a direct impact on selfish behaviour in situations where the opponent does not have any opportunity to modify a decision (as is the case in the dictator game), and it is plausible to assume that it is weakened in social situations (e.g., the ultimatum game), in which fairness norms and punishment sentiments of the opponent need to be considered. Taking this view, it seems also plausible that individuals with a highly developed power motive should make relatively strong efforts in assessing the strategic attitudes of the opponent in strategic situations like the ultimatum game, in order to estimate how far they can go without burning the money. This consideration is in line with van Lange and Kuhlman (1994) who found that in social dilemmas competitive individuals (i.e. in our interpretation individuals with high power motivations) evaluate their opponents with respect to their intelligence, whereas cooperative subjects evaluate their opponents with respect to their morality. Future research is needed to investigate these assumptions, for example, by directly manipulating this aspect.

The present study ties on older studies (Terhune 1968; Schnackers and Kleinbeck 1975) that also pointed to the role of the implicit power motive in socio-economic decision-making. Except for these few studies, this issue has not been a focus of extant systematic investigation yet. Particularly, the aspect of implicitness may be fruitful in economic research because previous research has demonstrated that implicit (indirectly assessed) aspects are advantageous in predicting non-deliberate behaviour, whereas explicit (directly assessed) aspects are advantageous in predicting socially desirable behaviour (Asendorpf et al. 2002; McClelland et al. 1989a, b). Therefore, whenever decisions are made that can be expected to be barely 
influenced by social desirability tendencies, implicit measures may be more appropriate to predict such decisions.

Positive affect was significantly associated with self-allocation but not with other-allocation, even after behaviour consistency was controlled for. Consequently, positive affect influenced selfish behaviour independently from a potential lack of task motivation. This finding is congruent with Personality Systems Interactions theory, which relies on the notion of a independent effects of positive and negative affects. Specifically, the presence of positive but not the absence of negative affect supports the enactment of intentions, whereas the presence of negative affect but not the absence of positive affect presumably constricts the spectrum of action alternatives and primes rigid behaviour (Kuhl 2000, 2001). This interpretation is congruent with previous research (Hertel and Fiedler 1998; Sanna et al. 2003), showing that positive affect supports selfish behaviour when selfish schemas or goals were primed beforehand.

Furthermore, our data suggest that the implicit power motive and positive affect influence individualistic behaviour independently. By contrast, the effect of the explicit power motive on individualistic behaviour could be explained by the effect of positive affect, which was positively correlated with the explicit power motive. This finding may reflect a general energetic component of experienced power (Keltner et al. 2003). Consequently, an explicit (but not implicit) power motive may result in positive affect, which in turn may provide energy to pursue one's individualistic goals. This interpretation is consistent with neuroscientific research suggesting that the left frontal cortex of our brain supports both approach-related positive affect (Davidson 1993; Harmon-Jones 2007) as well as the power motive (Kuhl and Kazén 2008; Quirin et al. 2008) and power-related emotions such as anger (Harmon-Jones and Siegelman 2001). Notably, this hemisphere seems to be specialized on linear thinking in terms of means-end relationships (Levy and Trevarthen 1976) whereas the right hemisphere is related to a more creative cognitive style operating within extended experiential networks (Bowden et al. 2005). A means-end focus has been postulated as a basic component of the power motive (Veroff 1957; Winter 1994). In contrast to explicit sources of power motivation, implicit power needs may operate more spontaneously and thus more effortlessly, requiring less energy to pursue corresponding goals. However, further research is needed to shed more light on the causal network between power motive and positive affect in influencing individualistic behaviour.

It should be noted that to our best knowledge the majority of studies that have investigated the influence of affect on selfish or prosocial behaviour have not differentiated between positive and negative affect but regarded them as opposite poles of one dimension (cf. Cacioppo et al. 1999; Tellegen et al. 1999, for discussions on the structure of affect). Thus, our findings on a unique influence of positive affect suggest that differentiating between the two affective components is a promising attempt to shed more light on the yet underexposed role of affective processes in economic decision-making.

The present results are in line with many studies claiming that the traditional notion of homo oeconomicus who bases economic decisions exclusively on rational thoughts about profit maximization is insufficient. Prominently, the accurateness of 
the implicit power measure was above the explicit measure. Implicit motive measures tap into aspects of personality of which the individual is not necessarily aware of but nevertheless exert an influence on behaviour (McClelland et al. 1989a, b). Likewise, affective states can influence behaviour without the individual knowing about this influence, even if the individual is aware of his current affective states. Therefore, both the implicit power motive and affective states have probably had an automatic influence on the socio-economic decisions made in the present study. Therefore, future research about socio-economic decisions should consider the distinction between implicit and explicit power motivations and investigate the implications of these motivations on economic decisions. The results so far are congruent with contemporary research on the influence of intuitive or automatic processes on human behaviour in general (Bargh et al. 1996) and in economic decisions in particular (e.g., Dijksterhuis 2004; Dijksterhuis et al. 2006). A vast neuroscientific research program evidences that much of our decisions are based on intuitive and non-deliberate processes. Specifically, regions that are not bound to rational deliberation such as the ventromedial prefrontal cortex revealed to be strongly involved in appropriate economic decision-making that is sensitive and flexibly adapts to contextual factors such as situational changes or the reactions of interested parties (see Bechara and Damasio 2005).

The present study is not without limitations. Specifically, previous research suggests that the power motive can also foster prosocial behaviour in certain situations (e.g., McClelland 1970; Winter and Barenbaum 1985). Specifically, in cases where an interaction partner who can be advised or supported by the actor (as example of prosocial leadership), the actor's power motive might even trigger prosocial behaviour. However, because our experimental settings involved nonvisibility, non-presence, and anonymity of the other player, leadership motivation promoting prosocial leadership may not have been aroused (participants were only aware that the other player existed and that the money left to this player would be transferred to him).

Acknowledgments We thank Stephan Dickert for comments on an earlier version of this paper, and Brian Cooper for linguistic revisions.

Open Access This article is distributed under the terms of the Creative Commons Attribution Noncommercial License which permits any noncommercial use, distribution, and reproduction in any medium, provided the original author(s) and source are credited.

\section{References}

Aiken LS, West SG (1991) Multiple regression: testing and interpreting interactions. Sage Publications, Inc, Newbury Park, CA

Asendorpf JB, Banse R, Mücke D (2002) Double dissociation between implicit and explicit personality self-concept: the case of shy behavior. J Pers Soc Psychol 83:380-393

Bargh JA, Chen M, Burrows L (1996) Automaticity of social behavior: direct effects of trait construct and stereotype activation on action. J Pers Soc Psychol 71:230-244

Baron RM, Kenny DA (1986) The moderator-mediator variable distinction in social psychological research: conceptual, strategic, and statistical considerations. J Pers Soc Psychol 51:1173-1182 
Baumann N, Kaschel R, Kuhl J (2005) Striving for unwanted goals: stress-dependent discrepancies between explicit and implicit achievement motives reduce subjective well-being and increase psychosomatic symptoms. J Pers Soc Psychol 89:781-799

Bechara A, Damasio AR (2005) The somatic marker hypothesis: a neural theory of economic decision. Game Econ Behav 52:336-372

Bolton GE, Ockenfels A (2000) ERC: a theory of equity, reciprocity, and competition. Am Econ Rev 90:166-193

Bornstein RF (2002) A process dissociation approach to objective-projective test score interrelationships. J Pers Assess 78:47-68

Bowden EM, Jung-Beeman M, Fleck J, Kounios J (2005) New approaches to desmystifying insight. Trends Cogn Sci 9:322-328

Brandstätter H, Königstein M (2001) Personality influences on ultimatum bargaining decisions. Eur J Personality 15:53-70

Brosig J (2002) Identifying cooperative behavior: some experimental results in a prisoner's dilemma game. J Econ Behav Organ 47:275-290

Cacioppo JT, Gardner WL, Berntson GG (1999) The affect system has parallel and integrative processing components: form follows function. J Pers Soc Psychol 76:839-855

Camerer CF (2003) Behavioral game theory: experiments in strategic interaction. Russell Sage Foundation, New York

Carlson M, Charlin V, Miller N (1988) Positive mood and helping behavior: a test of six hypotheses. J Pers Soc Psychol 55:211-229

Carver CS, Scheier MF (2004) Perspectives on Personality, 5th edn. Allyn and Bacon, Boston

Davidson RJ (1993) Cerebral asymmetry and emotion: conceptual and methodological conundrums. Cogn Emot 7:115-138

Davis-Blake APJ (1989) Just a mirage: the search for dispositional effects in organizational research. Acad Manage Rev 14:385-400

de Mesquita BB, McDermott R (2004) Crossing no man's land: cooperation from the trenches. Polit Psychol 25:271-287

Dijksterhuis A (2004) Think different: the merits of unconscious thought in preference development and decision making. J Pers Soc Psychol 87:586-598

Dijksterhuis A, Bos MW, Nordgren LF, van Baaren RB (2006) On making the right choice: the deliberation-without-attention effect. Science 311:1005-1007

Donley RE, Winter DG (1970) Measuring the motives of public officials at a distance: an exploratory study of American presidents. Behav Sci 15:227-236

Fehr E, Gächter S (2002) Altruistic punishment in humans. Nature 415:137-140

Fehr E, Schmidt K (1999) A theory of fairness, competition, and cooperation. Q J Econ 114:817-868

Fessler DM, Haley KJ (2003) The strategy of affect: emotions in human cooperation. In: Hammerstein P (ed) Genetic and cultural evolution of cooperation, MIT Press, pp 7-36

Gürerk Ö, Irlenbusch B, Rockenbach B (2006) The competitive advantage of institutions. Science 312:108-111

Harmon-Jones E, Sigelman J (2001) State anger and prefrontal brain activity: evidence that insult-related relative left-prefrontal activation is associated with experienced anger and aggression. J Pers Soc Psychol 80:797-803

Haselhuhn MP, Mellers BA (2005) Emotions and cooperation in economic games. Cognitive Brain Res 23:24-33

Heath A (1976) Rational choice and social exchange. Cambridge University Press, Cambridge

Henrich J, Boyd R, Bowles S, Camerer C, Fehr E, Gintis H et al (2005) 'Economic Man' in cross-cultural perspective: ethnography and experiments from 15 small-scale societies. Behav Brain Sci 28: $795-855$

Hertel G (1999) Mood effects in social dilemmas: what we know so far. In: Foddy M, Smithson M, Schneider S, Hogg M (eds) Resolving social dilemmas: dynamic, structural and intergroup aspects. Psychology Press, New York, pp 227-244

Hertel G, Fiedler K (1994) Affective and cognitive influences in a social dilemma game. Eur J Soc Psychol 24:131-145

Hertel G, Fiedler K (1998) Fair and dependent versus egoistic and free: effects of semantic and evaluative priming on the "Ring Measure of Social Values". Eur J Soc Psychol 28:49-70

Hertel G, Neuhof J, Theuer T, Kerr NL (2000) Mood effects on cooperation in small groups: does positive mood simply lead to more cooperation? Cogn Emot 14:441-472 
Kahneman D, Tversky A (1996) On the reality of cognitive illusions. Psychol Rev 103:582-591

Keltner D, Gruenfeld DH, Andersen C (2003) Power, approach, and inhibition. Psychol Rev 110:265-284

Krohne HW, Egloff B, Kohlmann C-W, Tausch A (1996) Untersuchungen mit einer deutschen Version der "Positive and Negative Affect Schedule" (PANAS). Diagnostica 42:139-156

Kuhl J (1999) Der Motiv-Umsetzung-Test (MUT) [The motive enactment test]. Unpublished test, University of Osnabrück, Osnabrück

Kuhl J (2000) A functional-design approach to motivation and self-regulation: the dynamics of personality systems and interactions. In: Boekaerts M, Pintrich PR (eds) Handbook of selfregulation. Academic Press, San Diego, pp 111-169

Kuhl J (2001) Motivation und Persönlichkeit. Interaktionen psychischer Systeme [Motivation and personality: interactions of mental systems]. Hogrefe, Göttingen

Kuhl J (2005) TOP Manual. Osnabrück: Universität Osnabrück, IMPART GmbH

Kuhl J, Kazén M (1999) Volitional facilitation of difficult intentions: joint activation of intention memory and positive affect removes stroop interference. J Exp Psychol Gen 128(3):382-399

Kuhl J, Kazén M (2008) Motivation, affect, and hemispheric asymmetry: power versus intimacy. J Pers Soc Psychol (in press)

Kuhl J, Scheffer D (1999) Der operante Multi-Motiv-Test (OMT): manual. Unpublished manuscript, Universität Osnabrück

Kuhl J, Scheffer D, Eichstaedt J (2003) Der Operante Motiv-Test (OMT): Ein neuer Ansatz zur Messung impliziter Motive. In: Rheinberg F, Stiensmeier-Pelster J (eds) Diagnostik von Motivation und Selbstkonzept. Hogrefe, Göttingen, pp 129-149

Kuhl J, Kazén M, Koole SL (2006) Putting self-regulation theory into practice: a user's manual. Appl Psychol 55:408-418

Lerner JS, Small DA, Loewenstein G (2004) Heart strings and purse strings: carryover effects of emotions on economic decisions. Psychol Sci 5:337-341

Levy J, Trevarthen C (1976) Metacontrol of hemispheric functions in human split brain patients. J Exp Psychol 2:299-312

Lewicki RJ, Litterer JA,Minton JW, Saunders DM (1994) Negotiation. Burr Ridge, Boston

Liebrand WBG, Dehue FMJ (1996) Social Values. In: Manstead ASR, Hewstone M (eds) The Blackwell encyclopedia of social psychology, vol 1. Blackwell, Oxford, pp 609-614

Liebrand WB, McClintock CG (1988) The ring measure of social values: a computerized procedure for assessing individual differences in information processing and social value orientation. Eur $\mathrm{J}$ Personality 2:217-230

Liebrand WB, Jansen RW, Rijken VM, Suhre CJ (1986) Might over morality: social values and the perception of other players in experimental games. J Exp Soc Psychol 22:203-215

List JA (2007) On the interpretation of giving in dictator games. J Polit Econ 115(3):482-493

McCabe K, Rigdon ML, Smith VL (2003) Positive reciprocity and intentions in trust games. J Econ Behav Organ 52:267-275

McClelland DC (1970) The two faces of power. J Int Aff 24:29-47

McClelland DC, Koestner R, Weinberger J (1989a) How do self-attributed and implicit motives differ? Psychol Rev 96:690-670

McClelland DC, Koestner R, Weinberger J (1989b) How do self-attributed and implicit motives differ? Psychol Rev 96:690-702

Murray HA (1943) Thematic apperception test manual. Harvard University Press, Cambridge, MA

Nicklisch A (2006) Wage differentials, fairness, and social comparison: an experimental study of interrelated ultimatum bargaining (No. 2006/8). Max-Planck-Institute for Research on Collective Goods, Bonn

Poppe M, Valkenburg H (2002) Effects of gain versus loss and certain versus probable outcomes on social value orientations. Eur J Soc Psychol 33:331-337

Powers WT (1973) Behavior: the control of perception. Aldine, Chicago

Quirin M, Kazén M, Hardung N, Kuhl J (2008) Hemisphere asymmetry in affiliation and power: investigating resting EEG alpha in social motives. Submitted for publication

Rogers T, Bazerman MH (2008) The emergence of affect in negotiations research. In: Sander D, Scherer KR (eds) The Oxford companion to the affective sciences. Oxford University Press (in press)

Rubinstein A (1998) Modeling bounded rationality. MIT Press, Cambridge

Sanna LJ, Parks CD, Chang EC (2003) Mixed-motive conflict in social dilemmas: mood as input to competitive and cooperative goals. Group Dyn-Theor Res 7:26-40 
Scheffer D (2001) Entwicklungsbedingungen impliziter Motive. Dissertation thesis, University of Osnabrueck. Web site: http://elib.ub.uni-osnabrueck.de/publications/diss/E-Diss150_thesis.pdf

Scheffer D, Kuhl J, Eichstaedt J (2003) Der Operante Motiv-Test (OMT): Inhaltsklassen, Auswertung, psychometrische Kennwerte und Validierung. In: Rheinberg F, Stiensmeier-Pelster J (eds) Diagnostik von Motivation und Selbstkonzept. Hogrefe, Göttingen, pp 151-168

Scheres A, Sanfey AG (2006) Individual differences in decision making: drive and reward responsiveness affect strategic bargaining in economic games. Behav Brain Funct 2:2-35

Schnackers UK, Kleinbeck U (1975) Power motive and power thematic behavior in a bargaining game. Archiv für Psychologie 127:300-319

Tellegen A, Watson D, Clark LA (1999) On the dimensional and hierarchical structure of affect. Psychol Sci 10:297-303

Terhune KW (1968) Motives, situation, and interpersonal conflict within prisoner's dilemma. J Pers Soc Psychol 8:1-24

Thompson LL (1990) Negotiation behavior and outcomes: empirical evidence and theoretical issues. Psychol Bull 108:515-532

Uleman JS (1966) A new TAT measure of the need for power. Unpublished Doctoral thesis, Harvard University

Van Lange PAM, Kuhlman DM (1994) Social value orientations and impressions of partner's honesty and intelligence: a test of the might versus morality effect. J Pers Soc Psychol 67:126-141

Veroff J (1957) Development and validation of a projective measure of power motivation. J Abnorm Soc Psych 54:1-8

Watson D, Clark LA, Tellegen A (1988) Development and validation of brief measures of positive and negative affect: the PANAS scales. J Pers Soc Psychol 54:1063-1070

Winter DG (1973) The power motive. The Free Press, New York

Winter DG (1987) Leader appeal, leader performance, and the motive profiles of leaders and followers: a study of American presidents and elections. J Pers Soc Psychol 52:196-202

Winter DG (1994) Manual for scoring motive imagery in running text (Version 4.2). University of Michigan

Winter DG, Barenbaum NB (1985) Responsibility and the power motive in women and men. J Pers 53:335-355 